\title{
Vídeo em contexto educacional: representação de alunos de mestrado em psicologia escolar
}

\author{
Eliana Martins da Silva Rosado \\ PUC-Campinas
}

\author{
Neila Pellegrina Benzi \\ CNPq/PUC-Campinas
}

\author{
Regina Maria Prado Leite Erbolato \\ CAPES/PUC-Campinas
}

Os objetivos foram explorar o conteúdo de representações de pós-graduandos em psicologia escolar sobre o uso do vídeo no ensino-aprendizagem e a complexidade da argumentação apresentada pelos sujeitos, utilizando-se o referencial teórico de Moscovici. 29 sujeitos preencheram um questionário, sendo feitas análises estatística e de conteúdo dos dados. Os principais resultados revelaram que as concepções dos sujeitos basearam-se mais em aspectos ligados à dimensão prática do uso do vídeo (vivência de docência) do que resultantes de uma reflexão teórica sobre o assunto. As vantagens da linguagem audiovisual foram atribuidas ao aumento de motivação e melhoria do clima de aprendizagem; as desvantagens, à falta de capacitação do professor e mau uso do vídeo. Conforme sugerido pela teoria, concluiu-se que a evolução das representações sobre um dado objeto social acontece lentamente; também mostrou-se pertinente o uso do conceito de representação social na exploração desse tema.

Palavras-chave: análise de conteúdo, situação educacional, linguagem audiovisual, pós-graduandos, questionário, representação social.

\begin{abstract}
The video in educational setting:

representations of students attending School Psychology graduation

The objectives were to explore: the content of representations on the use of video in educational setting among students attending School Psychology graduation, and the complexity of the argumentation presented by the subjects, according to Moscovici's theoretical framework. A questionnaire was filled by 29 subjects. The data were submitted to statistical and thematic content analysis. The main results revealed that the subjects conceptions were chiefly based on features related to the practical dimension of the usage of video (teaching experience) rather than a result of a theoretical reflexion on the theme. The advantages of the audiovisual language were related to an increase of motivation and improvement of the learning atmosphere, and disadvantages due to teacher's lack of empowerment and video misusage. As theory suggests, one can conclude that the evolution of representations on a given social object takes place slowly. The employment of the concept of representation in exploring this subject matter also demonstrated to be pertinent.

Key words: audiovisual language, content analysis, educational setting, graduation students, questionaire, social representation.
\end{abstract}

\section{Contextualização do trabalho e objetivos}

Trabalhar a questão que envolve o uso de novas tecnologias de formação e de informação no processo ensino-aprendizagem supõe abar- car um grande número de variáveis que colaboram para o sucesso ou fracasso de um investimento dessa natureza. Além disso, atualmente em nosso país, a gama de recursos utilizados é no mínimo mal distribuída: por um

Endereço para correspondência: Departamento de Pós-Graduação em Psicologia - PUC-Campinas, Rua Waldemar César da Silveira, 105, Swift, CEP 13045-270, Campinas, SP. 
lado, bastante vasta e variada para alguns indivíduos privilegiados que freqüentam escolas particulares, enquanto que bem menos promissora para outros que enfrentam penúrias ligadas à ausência da infra-estrutura mínima necessária para que o aprendizado possa ocorrer.

Diversas instâncias colaboram para tanto: políticas governamentais, que iniciam projetos envolvendo novas tecnologias e educação e que freqüentemente não chegam à termo; ausência de continuidade de projetos já implantados por questões ligadas às mudanças governamentais e/ou por falta de engajamento dos diferentes setores responsáveis, que acabam por abortar ações promissoras enquanto desperdiça-se o dinheiro público com falta de manutenção de aparelhos, infra-estrutura física e de recursos humanos insuficientes para a concretização dos planos; diretores de escolas, que acabam por vezes privilegiando a presença e o uso de tecnologias, sem que haja uma verdadeira preocupação pedagógica subjacente...

Há também que se considerar os professores envolvidos no processo: enquanto alguns por vezes arcam pessoalmente com despesas para trazerem à sala de aula suportes que, a seu ver, auxiliariam no processo de aprendizagem, outros mostram-se reticentes quanto ao uso de recursos já disponíveis em função de dificuldades diversas tais como falta de capacitação, receios, preconceitos, etc (Rosado,1994a). Isso tudo sem esquecer do aluno que, com suas próprias potencialidades, capacidades, motivações, expectativas e valores, acaba facilitando ou rejeitando a entrada de suportes tecnológicos no processo ensino-aprendizagem.

A complexidade do tema não é novidade e qualquer atividade de pesquisa cuidadosa nessa área exige um recorte da realidade, no sentido de privilegiar-se uma faceta do problema de modo a gerar elementos que permitam uma melhor compreensão desse objeto. Nesse sentido, cursos de pós-graduação, especificamente aqueles voltados ao campo da Psicologia Escolar, pareceram constituir um terreno de análise interessante para que se possa estudar a questão do uso de novas tecnologias na educação, por uma série de razões:

1. os profissionais que ingressam nesses cursos têm, habitualmente, uma experiência em docência em qualquer um dos níveis de escolaridade. Embora possa não ser esse o caso da totalidade desses profissionais, grande parte deles normalmente puderam vivenciar o que seja encontrar-se diante de uma classe, tendo portanto uma certa "idéia" de ensino-aprendizagem em sala de aula. Com base no conceito de representação social de Moscovici (1978), essa idéia poderia ser chamada de representação do que seja ensinar-aprender ou de modelo implícito de aprendizagem. Dentro deste referencial teórico, o posicionamento de um indivíduo em relação ao uso de recursos (em ocorrência o uso de vídeo para o ensino-aprendizagem) pode ser visto como um dos aspectos que revelam sua representação do objeto (ensinar e aprender com o auxílio de vídeo). Seu posicionamento pode ser caracterizado pela "distância" estabelecida entre o sujeito e o objeto. Essa "distância" pode ser avaliada por modelos teóricos diversos, tal como suposto no referencial neobehaviorista (Osgood, Suci \& Tannenbaum, 1957) que define eixos como avaliação, potência e atividade como fatores que permitem o estudo de representações. É portanto possível explorar-se a representação de sujeitos através de indicadores como a idéia que elaboram sobre um objeto, mas também através da avaliação que fazem deste determinado objeto;

2. parte desses profissionais tiveram a oportunidade, se não de usar, pelo menos de estar junto de um grupo de docentes que faziam uso de produtos e suportes diversos, tendo portanto par- 
ticipado das dificuldades, vantagens/ desvantagens e interrogações que tal emprego gera. Isso leva a outro conjunto de representações, ou seja, aquelas que envolvem o espaço, $a$ pertinência, o status do uso de tecnologias na educação. Privilegiar-se os indicadores vantagens e desvantagens do uso de vídeo no ensinoaprendizagem acha-se em acordo com o objetivo de explorar as representações desses sujeitos diante deste objeto. Habitualmente, existe o confronto entre o posicionamento que reflete um discurso dominante sobre televisão/linguagem audiovisual como geradores de passividade e mediocridade em contraposição à outra ótica que traduz o posicionamento do sujeitotelespectador como participante ativo no processo de reconstrução do sentido das mensagens audiovisuais (Bélisle et al.,1988; Rosado,1990,1992,1994b). Esses dois polos determinam o universo dos dois principais eixos de reflexão sobre as relações entre vídeo e aprendizagem encontrados no espaço escolar. ${ }^{1}$ Para reduzir o universo das tecnologias de ensino aqui visadas (o que seria exigido para o desenrolar de uma atividade científica), situaremos o video em salas de aula como um representante dessas tecnologias. Isso porque, dentre outras tantas razões, vê-se atualmente uma maior articulação entre a linguagem audiovisual, ou a imagem animada, impulsionada também pelo emprego de recursos como a informática na educação. Assim, as representações que aqui interessariam serem abordadas são as relativas ao uso do vídeo em salas de aula;

3. muitos desses profissionais, psicólogos ou não psicólogos, têm formação em Pedagogia, Magistério, Letras, etc, o que obrigatoriamente os teria colocado em contato com problemáticas diversas ligadas à educação, bem como a aspectos referentes a métodos de ensino, recursos, etc;

4. por estarem engajados em um curso de pósgraduação em Psicologia Escolar, seria de se esperar que, senão a totalidade, pelo menos grande parte desses profissionais se interessasse pelas questões ligadas à educação em geral e a aspectos da relação ensino-aprendizagem em particular. Nesse sentido, fica difícil não se ter ao menos um olhar sobre as relações entre tecnologias e ensino, mesmo que as problemáticas escolhidas por esses profissionais para serem trabalhadas em suas pesquisas fossem outras, tais como prevenção, dificuldades de aprendizagem, avaliação, relação professoraluno, etc. Não é difícil sustentar que, dentro dessas problemáticas, acaba existindo alguma forma de tecnologia, e portanto, funcionando como variável no processo;

5. o ingresso na pós-graduação supõe a participação desses profissionais em ações voltadas para a sua aprendizagem na atividade científica. Para tanto, busca-se desenvolver no mestrando uma postura mais crítica, que exija gradualmente do mesmo formulações de problemas, de hipóteses, o desenvolvimento de argumentações sustentadas por dados comprovados, ou ao menos o esforço de chegar-se a essa forma de abordar a realidade, sem a qual não se pode dizer que se faz pesquisa, mas sim conjecturas a respeito de um objeto de estudo. Assim, esperar-se-ia que as argumentações desses profissionais pudessem estar fornecendo um rico material de estudo, não só em termos de conteúdo sobre a

1. É importante salientar que a ótica da reconstrução do sentido por parte do sujeito não é formulada como tal no discurso social de professores adeptos do uso da linguagem audiovisual no ensino-aprendizagem. No entanto, os pressupostos subjacentes a esse posicionamento poderiam mais facilmente ser acrescidos dos elementos de reflexão contidos na problemática da reconstrução do sentido do que num posicionamento que reflita os efeitos, quase sempre nefastos, da mídia sobre o sujeito. 
temática estudada, mas também maior reflexão sobre as experiências cotidianas em salas de aula do que outros profissionais com orientações diversas talvez pudessem oferecer;

6. enquanto pós-graduando, o objetivo maior desse profissional é o de realizar sua própria pesquisa, o que inevitavelmente exigirá a colaboração de sujeitos num procedimento de coleta de dados. Muito se fala sobre as dificuldades em se obter informações dos sujeitos, para por exemplo, responder a um questionário. O exercício de inversão de papéis, ou seja, a solicitação a pós-graduandos de funcionarem como sujeitos de pesquisa, poderia ser visto como uma situação formadora, já que propiciaria uma experiência a esses profissionais, de atuarem dentro do "setting" de respondente de questionário, avaliando dificuldades, limitações, dúvidas e posicionamentos diante de tal instrumento, contexto frente ao qual colocarão seus sujeitos dentro de suas próprias pesquisas.

Essas considerações pareceram, a nosso ver, suficientes para justificar a realização de um levantamento feito junto a alunos de um curso de pós-graduação em Psicologia Escolar sobre a problemática que envolve o uso do vídeo em salas de aula. Dentro da amplitude que esta problemática abarca, a dimensão psicossocial foi privilegiada: o conceito de representação social, ou seja, as idéias, concepções, percepções que pós-graduandos em Psicologia Escolar (habitualmente com experiência docente) têm das relações entre vídeo e processo de aprendizagem, constituiu o elemento teórico central do trabalho.

Isso porque, segundo Moliner (1996), poder referir-se a um objeto ou a um sistema de conhecimentos significa ter desenvolvida a habilidade de identificar esse objeto, de colocar-se em condições de compreender as situa- ções e acontecimentos relacionados a ele, além de poder tecer previsões a seu respeito. Desse modo, a função das representações é equivalente a de uma teoria do ambiente social, fornecendo noções prontas para o uso por parte do indivíduo (condicionando suas condutas). Tais teorias fornecerão um sistema de relações entre as noções, permitindo a interpretação, a explicação e a predição tanto do ambiente em si, como do sujeito interagindo nesse ambiente.

Do ponto de vista teórico, uma representação social é uma construção mental elaborada pelo indivíduo em sua interação com o ambiente físico e social que o rodeia. Desse modo, as representações correspondem à dimensão simbólica que toma parte na elaboração da ação e, ao mesmo tempo, referem-se à prática que produz esse conteúdo simbólico (Moscovici, 1978). Tal interação pode dar-se através de uma prática efetiva (no caso, decorrente do uso do produto vídeo pelo sujeito, enquanto professor, em situação real de aprendizagem), de trocas de informações com pares (conversas, experiências de colegas utilizadores de vídeo em sala de aulas) ou ser mediatizada (meios de comunicação em geral).

Segundo Jodelet (1984), as representações sociais apresentam-se sob forma de imagens que condensam conjuntos de significados, sistemas de referências que permitem ao indivíduo interpretar o que lhe acontece, dando sentido ao inesperado, ao desconhecido; tratam-se de categorias que servem para classificar indivíduos, situações, fenômenos. Um elemento fundamental para o presente trabalho está na perspectiva de se ver as representações sociais como uma forma de conhecimento elaborado e compartilhado socialmente, que modula as condutas dos indivíduos em situações contextualizadas. Jodelet afirma que "a representação deve ser abordada como o produto e o processo de uma elaboração psicológica e so- 
cial do real" (p.361), cujos mecanismos utilizados para sua construção situam-se necessariamente em dois níveis: parte do individual atingindo o coletivo.

Em termos práticos, o pressuposto que sustenta serem essas construções uma forma de conhecimento abre uma via de pesquisa importante para os estudiosos da problemática que relaciona tecnologias e contexto de ensino: na medida em que a prática do indivíduo com, por exemplo o vídeo, será modulada por essa visão particular do suporte, é possível relativizar-se as contribuições efetivas de um determinado produto (vídeo) dentro da aprendizagem, em função de uma análise cuidadosa do método efetivamente empregado pelo professor quando do recurso a esse suporte em sua atividade acadêmica. Falar que um vídeo em especial ou que a linguagem audiovisual traz benefício (ou não) à aprendizagem, só poderá ocorrer quando se souber comv o professor introduziu o produto em seu programa, que tipo de atividades propôs aos alunos, de que natureza é sua relação com a linguagem audiovisual em termos de sua função e status dentro do ensino-aprendizagem e dentro do seu papel como professor. Explorar os indicadores vantagens e desvantagens de uso de vídeo em sala de aula não parece ter sido objeto de estudo privilegiado por pesquisadores em Psicologia ou Educação: no intervalo de 199798, não se encontrou trabalhos que versassem sobre essa temática (Psyclit). É bem verdade que a dimensão psicossocial (via estudo de representação social) como variável interveniente na relação professor-recurso vídeo no ensino-aprendizagem não tem sido tema de investigação para quem estuda tecnologias de ensino e educação. Quatro eixos principais tem constituído esse campo de produção científica no Brasil:

a) trabalhos que focalizam a construção das mensagens, via análise de conteúdo de emis- sões de TV, sem que a ligação com a educação (especificamente a realidade de sala de aula) seja necessariamente explicitada (Pacheco, 1985,1991; Witter, 1992);

b) trabalhos que privilegiam a operacionalização do uso de vídeo no ensino-aprendizagem, sem que no entanto haja um maior aprofundamento teórico dos aspectos psicológicos subjacentes ao mesmo (Moran, 1990);

c) eixos de reflexão que tomam como ótica uma visão mais "macro" das relações entre televisão e escola, buscando formas de integração entre esses universo e/ou investigando as dificuldades de articulação dos mesmos (Penteado, 1991);

d) campos de investigação que trabalham a tecnologia dentro da relação ensino-aprendizagem, focalizando a formação do professor, numa abordagem cujas bases filosóficas acham-se enraizadas na ótica da leitura crítica da comunicação (Fusari, 1994).

Por outro lado, é importante ressaltar que, do ponto de vista teórico e das conclusões que se possam tirar dos dados, os cuidados com a precisão do conceito dentro dos limites que a sistematização de Moscovici (1978) propõe devem ser assegurados. Nas palavras de Jodelet (1984): o fato de que se situe a representação como forma de conhecimento "traz o risco de reduzi-la a um acontecimento intra-individual, onde o social intervém secundariamente. O fato de tratar-se de uma forma de pensamento social leva o risco de diluí-la nos fenômenos culturais ou ideológicos" (p. 361). Na perspectiva do presente trabalho, a proposta das autoras foi de situar, tal como sugere Jodelet (1984), a noção de representação (social) do vídeo na aprendizagem, na interface do psicológico e do social. A dimensão social contribuiu para a elabora- 
ção, manutenção e evolução da representação em função, por exemplo:

a) do contexto concreto no qual estão situados grupos e pessoas (no presente caso, contexto escolar);

b) da comunicação que se estabelece entre eles (desde trocas de experiências acerca do vídeo e de todas as outras temáticas que envolvem o trabalho em educação, evidenciando-se a especificidade das relações interpessoais e das relações entre papéis);

c) dos referenciais de apreensão da realidade fornecidos pela bagagem cultural de cada um envolvido na situação (desde elementos recolhidos via formação e capacitação desses docentes até concepções formuladas em sua experiência cotidiana fora do contexto escolar acerca do que seja ensinar, aprender, aluno, professor, conhecimento, etc);

d) dos códigos, valores e ideologias ligados às posições por eles assumidas frente a questões sociais específicas (por exemplo, visão da relação entre democratização do ensino e tecnologias, condição social das populações atendidas pela escola pública e uso por essa clientela de novas tecnologias de comunicação no ensino, ensino público e ensino privado versus espaço de tecnologias nessas realidades, etc).

Já a dimensão psicológica estará marcada pela particular escolha, pelo "colorido" que cada indivíduo dará aos conteúdos de representação que circulam no discurso do grupo social ao qual pertence quando organizados em sua própria representação sobre algo. Do "material comum" disponível aos componentes de um grupo social, cada sujeito que o compõe efetuará sua particular relação com o objeto em questão, determinada pela bagagem de experiência de vida do sujeito, por suas características pes- soais, sua história de vida. Como diz Jodelet (1984), mesmo em representações elementares, é possível evidenciar-se um processo de elaboração cognitiva e simbólica, que orientará as condutas. Assim, entendemos que embora um sujeito possa não ter totalmente claras para si as razões que o levam a agir e a posicionar-se de determinada maneira, por exemplo, em relação à linguagem audiovisual no ensino-aprendizagem (e, portanto, parte do conteúdo revelaria mais do discurso social do que de um discurso próprio), o posicionamento assumido refletirá, necessariamente, sua relação intersubjetiva com o objeto em questão, seus receios e interesses pessoais, seus desejos e expectativas, seus objetivos de vida e projetos pessoais, dentro dos quais o posicionamento em relação ao objeto se harmonizará. Com a experiência, a reflexão e a interação com o meio, a complexidade, cristalização ou evolução da representação se produzirão.

Foi pois, com esse referencial teórico que os objetivos do presente trabalho foram formulados.

\section{Objetivos}

Dois objetivos específicos nortearam o desenvolvimento do presente trabalho, que teve como meta geral estudar a representação que pós-graduandos têm do emprego do vídeo no ensino aprendizagem:

Objetivo especifico 1: caracterizar o conteúdo das representações desses profissionais, expresso através da linguagem escrita, acerca do uso do vídeo em salas de aula, privilegiando os polos "vantagens" e "desvantagens" do emprego do recurso no ensino-aprendizagem;

Objetivo especifico 2: analisar características da argumentação utilizada para o posicionamento tomado. 


\section{Metodologia}

\section{Sujeitos}

Compuseram a amostra deste levantamento inicial, 29 estudantes (de um total possível de 36 alunos) de pós-graduação em Psicologia Escolar, cursando uma universidade particular no interior do Estado de São Paulo. A maioria desses estudantes já tinha cursado pelo menos um semestre de disciplinas na PósGraduação (62\% da amostra), tendo portanto, certa familiaridade com o tipo de reflexão que caracteriza a atividade científica. Isso permitiu às autoras esperarem respostas aos questionários imbuídas de uma qualidade de argumentação que refletisse a experiência já adquirida no Mestrado.

Quanto à formação, cerca da metade da amostra $(48,27 \%)$ era composta por psicólogos escolares; a outra metade $(51,72 \%)$ distribuíase por sete diferentes formações: Pedagogia (17,24\%), Educação Física (10,34\%), Engenharia $(6,89 \%)$, Fonoaudiologia $(6,89 \%)$, Letras $(3,44 \%)$, História (3,44\%) e Comunicações $(3,44 \%)$. Nota-se que algumas dessas formações preparariam mais o profissional para o exercício da docência, como por exemplo: Pedagogia, Letras, História e Educação Física. Já as demais, como Engenharia, Fonoaudiologia e Comunicações, seriam bem mais caracterizadas pela dimensão profissionalizante. Vale lembrar que, exceto pelos cursos de Pedagogia e Letras (eventualmente), as demais formações, quando não feitas as opções para licenciatura, não são contempladas com cursos voltados para práticas de ensino, didática ou qualquer outro preparo para a docência. No entanto, profissionais com curso superior (de qualquer natureza) podem apresentar-se para trabalho como professor, sem que essa lacuna na formação seja vista como um obstáculo ao exercício da docência.
Além disso, é importante ressaltar que mesmo nas graduações de Pedagogia, cursos sobre uso de tecnologias de ensino, linguagem audiovisual e aprendizagem, não fazem parte das disciplinas habitualmente oferecidas aos formandos (Fusari,1986,1994; Silva,1986). Assim, as concepções acerca das contribuições da linguagem audiovisual ao ensino-aprendizagem, bem como conhecimentos sobre metodologias de utilização em salas de aula, ficam mais apoiadas em experiências vividas pelos próprios sujeitos, seja em sua vida como alunos; seja em sua prática de docência, seja através da troca de experiências com colegas, podendo ser igualmente através desta fonte, a base para a elaboração de teorias pessoais acerca das relações entre vídeo e aprendizagem.

A reorganização dos sujeitos em subgrupos por formação marcados pela maior ou menor orientação para a docência ou para a prática mostrou-se uma estratégia interessante a ser aprofundada neste estudo. Isso porque a maior ou menor vivência do processo ensino-aprendizagem desses profissionais poderia ter contribuído para uma reflexão de natureza diversa nesses grupos quanto a meios e suportes de ensino. Assim, as informações antes referidas sobre a formação dos mestrandos podem ser reorganizadas de acordo com sua ênfase: $34,46 \%$ com ênfase em docência (Pedagogia, Educação Física, Letras, História) e 65,49\% com ênfase em profissionalização (Engenharia, Fonoaudiologia, Comunicações, Psicologia).

Desta forma, constata-se que, do total da amostra, somente $34,46 \%$ dos sujeitos teriam alguma possibilidade de terem recebido uma formação que evidenciasse aspectos próprios do processo ensino - aprendizagem, e portanto, poderiam ter avaliado o espaço e a contribuição dos diferentes suportes tecnológicos (dentre os quais o vídeo) como elementos participantes nesse processo. Saliente-se que, desse total, os 
profissionais em Pedagogia (17,24\% dos sujeitos; e portanto menos de $20 \%$ da amostra) são os que teriam efetivamente maiores chances de terem abordado tal tema. Entretanto, sendo quase $50 \%$ da amostra composta por psicólogos escolares, poder-se-ia esperar desse subgrupo uma reflexão relativamente aprofundada, em termos de um questionamento acerca de suportes e métodos e suas contribuições na relação ensinoaprendizagem.

Se essa variável - formação - pareceu promissora pois favoreceria a reflexão sobre o processo ensino-aprendizagem, a prática docente deveria fornecer uma outra situação de igual relevância para tal questionamento. Nesse sentido, constatou-se que a grande maioria dos sujeitos $(89,65 \%)$ tinha experiência docente, enquanto que somente $10,34 \%$ da amostra não a possuía. Desse modo, fosse através da formação ou em decorrência da prática profissional, a grande maioria da amostra teria, em hipótese, experimentado situações que possibilitariam indagações sobre métodos de ensino, suportes didáticos, etc.

Quanto à experiência/familiaridade com o uso do vídeo, tem-se o seguinte: do total da amostra, 34,48\% dos sujeitos receberam alguma formação em utilização do vídeo, sendo a maioria deles não psicólogos. Além de cursos, pode-se supor que a prática em magistério ofereça oportunidade para uso de vídeo em salas de aula, contribuindo assim para a experiência/familiaridade com o recurso. Constatou-se que, dos 26 sujeitos com experiência em docência, $76,92 \%$ já haviam feito uso do vídeo em sala de aula.

Do total de sujeitos (29 indivíduos), 69\% tinham recorrido ao suporte pelo menos uma vez em sua vida profissional, enquanto que $31 \%$ deles nunca tinham se servido da linguagem audiovisual em sua prática. Desse mesmo con- junto de sujeitos, $35 \%$ deles tinham passado por formação acerca do uso e contribuições do vídeo no processo ensino-aprendizagem. Já $65 \%$ desses sujeitos não tinham recebido qualquer formação que tivesse proporcionado uma reflexão mais aprofundada sobre as relações entre linguagem audiovisual e processo de aprendizagem.

Resumindo, a amostra foi marcada pela característica profissionalizante da formação dos sujeitos (65\%), com um contigente maior de indivíduos com prática docente $(89,65 \%)$, sendo que mais da metade da amostra (69\%) tinha tido pelo menos uma experiência com vídeo lecionando, embora somente $34 \%$ da amostra tivesse passado por capacitação para esse fim.

\section{Instrumento}

Foi empregado um questionário, composto de três questões abertas e oito fechadas, com duas variáveis básicas a serem estudadas:

1. caracterização da amostra, que explorava os indicadores formação, experiência em docência, capacitação em uso de vídeo, experiência com o recurso na sala de aula;

2. representação dos sujeitos acerca do vídeo no ensino-aprendizagem, através da exploração dos indicadores "vantagens" e "desvantagens".

Contou-se ainda com um diferencial semântico, elaborado para a pesquisa a partir de elementos teóricos (informações de natureza bibliográfica) que orientaram a seleção dos pares de adjetivos apresentados no instrumento. ${ }^{2}$

\section{Procedimento}

Obtida a permissão dos docentes das disciplinas para a utilização de parte dos horários das aulas obrigatórias do curso, distribuiu-se

2. Os dados referentes ao diferencial semântico não fazem parte deste artigo. 
o instrumento após ter-se explicitado os objetivos da pesquisa. Os instrumentos deveriam ser respondidos individualmente, no momento de disponibilidade de cada aluno e serem retornados aos pesquisadores em data fixada. Para o controle numérico da população, foram conferidos o número de alunos matriculados e expressos em folha de presença da secretaria do curso.

\section{Resultados}

A estrutura de nossa investigação situou os sujeitos numa perspectiva de analisar suas representações segundo os polos vantagens-desvantagens do emprego deste recurso no processo ensinoaprendizagem. Evidentemente, outras óticas poderiam ter sido exploradas, mas a intenção das autoras era a de poder mobilizar as prováveis experiências dos sujeitos (de uso efetivo pelos indivíduos ou de contato através da experiência de colegas) e articulá-las com o objeto de nosso estudo. Explorar vantagens e desvantagens solicitaria dos sujeitos uma reflexão do emprego do recurso "contextualizado". Por um lado, essa perspectiva de reflexão favoreceria o levantamento de hipóteses de ação/conduta dos sujeitos relativas ao emprego do suporte em sua prática efetiva de sala de aulas, fornecendo elementos de compreensão sobre seu posicionamento diante do recurso (Objetivo específico 1).

Por outro lado, entende-se que tal ótica poderia, caso o sujeito se empenhasse para tanto, ser enriquecida com reflexões de outra natureza (teórica, como por exemplo, baseada em modelos de aprendizagem) o que forneceria indícios para se explorar, mesmo que a título de hipóteses, a questão relativa à complexidade da argumentação (Objetivo específico 2).

\section{$O$ conteúdo das representações relativas ao uso do vídeo no ensino-aprendizagem}

Tabela 1. Vantagens atribuídas ao uso didático do vídeo

\begin{tabular}{|c|c|c|c|c|c|}
\hline Categoriasglobais & $\mathbf{F}$ & $\%$ & Categorias finais & $\mathbf{F}$ & $\%$ \\
\hline $\begin{array}{l}\text { Ênfase em funçðes psicológicas } \\
\text { mobilizadoras no processo ensi- } \\
\text { no-aprendizagem }\end{array}$ & 21 & 24 & \multirow{2}{*}{$\begin{array}{l}\text { Uso do vídeo no processo ensino- } \\
\text { aprendizagem }\end{array}$} & \multirow{2}{*}{56} & \multirow{2}{*}{63} \\
\hline $\begin{array}{l}\text { Tipo de contribuiçðes no processo } \\
\text { ensino-aprendizagem }\end{array}$ & 35 & 39 & & & \\
\hline Caracteristicas do suporte em si & 33 & 37 & $\begin{array}{l}\text { Potencialidades do instrumento } \\
\text { no ensino-aprendizagem }\end{array}$ & 33 & 37 \\
\hline Total de argumentos & 89 & 100 & & 89 & 100 \\
\hline
\end{tabular}

3. A análise de conteúdo foi realizada segundo a técnica de Bardin (1996). 
1. $63 \%$ dos argumentos referiam-se à relação ensino-aprendizagem. Nela, a importância atribuída ao vídeo esteve em sua relação com o aluno, organizada segundo os grupos de argumentos abaixo:

- em $24 \%$ dos argumentos, o vídeo apareceu como elemento que "prepara" o aluno para a aprendizagem, que o mobiliza buscando seu investimento dentro do processo ensinoaprendizagem, sendo portanto anterior ao processo em si. Assim, tal como detalha a Tabela 2, atuar na motivação (7,26\% dos argumentos), atenção (7,26\%), mobilizar interesse $(5,61 \%)$, estimular $(2,24 \%)$ ou, mais genericamente, otimizar a aprendizagem $(12,35 \%$ do total de argumentos recolhidos) determinam aspectos que não evidenciam a função da linguagem audiovisual como uma ferramenta que possa interferir diretamente na aprendizagem. $\mathrm{O}$ que a linguagem audiovisual faria, segundo a concepção dos sujeitos, a rigor um professor com certo carisma, um livro didático de qualidade, um programa de computador ou um CD-Rom, poderiam fazer, já que em nenhum desses meios a especificidade de cada um parece focalizada preferencialmente. Dessa forma, a ênfase está nas qualidades mobilizadoras da linguagem audiovisual para garantir o investimento do sujeito na aquisição de conhecimentos;

- um total de $39 \%$ dos argumentos recolhidos buscaram detalhar o tipo de contribuição do vídeo na aprendizagem, porém enfatizando as mudanças que o mesmo provoca no " $c l i$ ma" da relação ensino-aprendizagem. O ví- deo funcionaria pois, como estimulador da ação $(5,61 \%)$, apontado genericamente como recurso didático $(21,30 \%)$, como instrumento de coleta de dados $(2,24 \%)$, evidenciando a presença da linguagem audiovisual - movimento e som sincronizados $(11,23 \%)$, porém sem a articulação precisa dessa linguagem dentro da aprendizagem, apresentada de maneira ampla como meio de comunicação $(13,40 \%$ do total de argumentos) (cf, Tabela 2). Essas modificações, porém, apareciam como exteriores ao processo de aprendizagem em si, que ocorre internamente no aluno.
Tabela 2. Detalhamento das vantagens do uso do vídeo no ensino-aprendizagem

\begin{tabular}{|l|c|c|c|c|c|}
\hline \multicolumn{1}{|c|}{ Categorias iniciais } & F & \% & Categorias globais & F & \% \\
\hline 1. motivação & 07 & 7,26 & Ênfase em funções psicológias & & \\
2. atenção & 07 & 7,26 & mobilizadoras do aprendizado & 21 & 24 \\
3. interesse & 05 & 5,61 & & & \\
4. estimulação & 02 & 2,24 & & & \\
5. otimizador aprendizagem & 11 & 12,35 & & & \\
\hline 6. estimulador da ação & 05 & 5,61 & Tipo de contribuições no pro- & & \\
7. recurso didático & 19 & 21,30 & cesso ensino-aprendizagem & 35 & 39 \\
8. instrumento coleta de dados & 02 & 2,24 & & & \\
9. linguagem audiovisual & 10 & 11,23 & & & \\
10. comunicação & 12 & 13,40 & & 33 & 37 \\
\hline 11. aspecto lúdico & 02 & 2,24 & Características do suporte em si & 33 \\
12. especificidade audiovisual & 07 & 7,86 & & $\mathbf{8 9}$ & $\mathbf{1 0 0}$ \\
\hline Total de argumentos & $\mathbf{8 9}$ & $\mathbf{1 0 0}$ & & & \\
\hline
\end{tabular}

Vale ressaltar que as três idéias gerais que compuseram o eixo das vantagens na representação (funções psicológicas mobilizadoras, contribuições na aprendizagem e características do suporte) não apresentaram diferença significativa $\left(\mathrm{x}^{2}{ }_{0}=3,87,2 \mathrm{gl}, \mathrm{p}=0,05\right)$, o que equivaleria a dizer que não há um conceito centralizador (visto em termos de categorias globais) que estruture essa dimensão das representações dos sujeitos diante do vídeo na aprendizagem. Do mesmo modo, as idéias que compuseram a categoria uso do vídeo no processo de aprendizagem, também não apresentaram diferença 
significativa $\left(\mathrm{x}^{2}{ }_{\mathrm{o}}=3,5,1 \mathrm{gl}, \mathrm{p}=0,05\right)$. Isso quer dizer que nem a questão da mobilização, tampouco as contribuições apontadas no processo de aprendizagem, são suficientemente presentes para assegurar um conceito centralizador que organize essa dimensão da representação dos sujeitos sobre as vantagens do vídeo na aprendizagem.

2. 37\% dos argumentos referiram-se aos aspectos próprios do vídeo enquanto instrumento è̀s suas vantagens potenciais, se comparado a outros recursos didáticos, mas sem contextualizá-los na relação ensino-aprendizagem.

A composição das diferentes categorias globais acha-se detalhada na Tabela 5, adiante.

- $49 \%$ dos argumentos enfatizaram o papel potencialmente negativo do professor na utilização do vídeo, evidenciando o uso inadequado (25,30\% dos argumentos) bem como sua falta de capacitação (13,24\%);ss

- apenas $15 \%$ das respostas referiram-se a possíveis problemas nas relações entre professor - aluno, e aluno - suporte, como decorrentes do emprego de vídeo no ensinoaprendizagem. Todavia, o estabelecimento de interações entre os elementos que comporiam a relação de aprendizagem terminaram aí. Não houve referências à interação professor - suporte; constatou-se que, segundo a visão desses sujeitos, o vídeo poderia interferir negativamente nas relações de aprendizagem, mas essas não eram vistas sob forma de uma tríade, como no caso das vantagens.

Tabela 3. Desvantagens atribuídas ao uso do vídeo no processo ensino-aprendizagem

\begin{tabular}{|c|c|c|c|c|c|}
\hline Categoriasglobais & $\mathbf{F}$ & $\%$ & Categorias finais & $\mathbf{F}$ & $\%$ \\
\hline $\begin{array}{l}\text { Ênfase nas condições de uso do } \\
\text { professor }\end{array}$ & 33 & 49 & \multirow{2}{*}{$\begin{array}{l}\text { Uso do vídeo no processo ensi- } \\
\text { no-aprendizagem }\end{array}$} & \multirow[t]{2}{*}{43} & \multirow[t]{2}{*}{64} \\
\hline $\begin{array}{l}\text { Ênfase nas relaçðes professor- } \\
\text { aluno e aluno-suporte }\end{array}$ & 10 & 15 & & & \\
\hline Ênfase na estrutura de uso & 06 & 09 & Infra-estrutura & 06 & 09 \\
\hline $\begin{array}{l}\text { Ênfase nas qualidades do pro- } \\
\text { duto em si }\end{array}$ & 18 & 26 & Características do suporte & 18 & 26 \\
\hline Não há inconvenientes & 01 & 01 & Sem desvantagens & 01 & 01 \\
\hline Total de argumentos & 68 & 100 & & 68 & 100 \\
\hline
\end{tabular}

Em relação às desvantagens atribuidas ao vídeo (Tabela 3 ), verificou-se a presença das duas idéias apontadas para as vantagens, além de duas novas perspectivas. Delas, a aplicação de prova não paramétrica permitiu identificar que a mesma referência usada para avaliar as vantagens do vídeo na aprendizagem fornece elementos para os sujeitos identificarem desvantagens do recurso na situação. Assim:

1. $64 \%$ dos argumentos estavam ligados à influência do vídeo no processo ensino - aprendizagem, da seguinte forma:
2. $9 \%$ das argumentações falavam da infra-estrutura da escola (condições físicas e acesso ao produto), sem uma ligação direta com as desvantagens do suporte, conforme o solicitado na questão;

3. $26 \%$ dos argumentos basearam-se nas características do produto em si, que tornam seu uso desvantajoso, apontando-se a obsolescência de produtos $(16,18 \%)$ tendo como um dos indicadores a má qualidade de imagens, pouca atualidade ou pouca precisão de conteúdos $(4,41 \%)$ bem como a presença de ideologias subjacentes a elementos de informação $(5,88 \%)$ como limitações importantes;

4. menos de 1,5\% das argumentações referiu-se à ausência de inconvenientes. 
Tabela 4. Detalhamento das desvantagens atribuídas ao uso do vídeo no processo ensino-aprendizagem

\begin{tabular}{|c|c|c|c|c|c|}
\hline Categorias iniciais & $\mathbf{F}$ & $\%$ & Categorias globais & $\mathbf{F}$ & $\%$ \\
\hline 1. metodologia de utilização & 24 & 25,30 & \multirow{2}{*}{$\begin{array}{l}\text { Ênfase nas condiçð̃es de uso } \\
\text { pelo professor }\end{array}$} & \multirow[t]{2}{*}{33} & \multirow{2}{*}{49} \\
\hline 2. capacitação professor & 09 & 13,24 & & & \\
\hline 3. relação suporte-aluno & 05 & 7,35 & \multirow{2}{*}{$\begin{array}{l}\text { Ênfase nas relaçzes professor- } \\
\text { aluno e aluno-suporte }\end{array}$} & \multirow[t]{2}{*}{10} & \multirow[t]{2}{*}{15} \\
\hline 4. relação professor-aluno & 02 & 7,35 & & & \\
\hline 5. condições físicas de uso & 02 & 2,94 & \multirow[t]{2}{*}{ Ênfase na estrutura de uso } & \multirow[t]{2}{*}{06} & \multirow[t]{2}{*}{09} \\
\hline 6. indisponibilidade/acesso & 04 & 5,88 & & & \\
\hline 7. qualidade do produto & 11 & 16,18 & \multirow{3}{*}{$\begin{array}{l}\text { Ênfase nas qualidades do } \\
\text { produto em si }\end{array}$} & \multirow[t]{3}{*}{18} & \multirow[t]{3}{*}{26} \\
\hline 8. conteúdo & 03 & 4,41 & & & \\
\hline 9. Ideologia subjacente & 04 & 5,88 & & & \\
\hline 10. sem inconvenientes & 01 & 1,47 & Não há inconvenientes & 01 & 01 \\
\hline Total de argumentos & 68 & 100 & & 68 & 100 \\
\hline
\end{tabular}

\section{Complexidade da argumentação apresentada}

O tratamento das informações recolhidas revelou que a grande maioria das respostas fornecidas trazia argumentos que se apoiavam muito mais na experiência efetiva dos sujeitos com o recurso, explorando alguns aspectos superficiais do processo ensino-aprendizagem relativos à questões como motivação, mobilização de interesse e de atenção, etc. Levando-se em conta que cerca de metade da amostra (48\%) era composta por psicólogos e que $62 \%$ dos sujeitos ingressara no pós-graduação há mais de um ano, poder-se-ia esperar que a complexidade das argumentações fosse maior, trazendo-se elementos teóricos mais elaborados para explicar as relações entre uso de representações simbólicas e aquisição de conhecimentos.

Todavia, a leitura, seja das categorias finais, seja das globais ou iniciais, indicou claramente que o nível de observação e de reflexão dos sujeitos não fugiu do que outras populações habitualmente usam, quando referem-se à problemática estudada. Em pesquisa feita com professores universitários, mas não necessariamente com formação em pósgraduação, respostas com argumentos mais variados, denotando uma maior reflexão diante da temática foram encontradas: algumas categorias como: interferência na memorização, concretização de conceitos abstratos etc (Rosado,1994a) compuseram o material recolhido junto àqueles sujeitos, que foram um pouco mais além em relação ao tipo de argumentação oferecida pela presente amostra. Saliente-se a brevidade das respostas escritas, sua pobre formulação na apresentação de idéias (via itemização) para citar somente algumas das qualidades que chamaram mais a atenção das autoras na análise dos dados.

Pouco interesse pelo trabalho solicitado? Pela área de investigação? Área de atuação diversa da pessoal, o que limitaria o grau de comprometimento dos sujeitos na pesquisa? Concepção negativa quanto ao uso de instrumento de coleta de dados sob forma de questionário? Limitação do grau de engajamento devida à situação de coleta de dados (dentro do horário de disciplinas do curso de pós-graduação)? Embora todas essas possibilidades possam ter sua importância e influência na qualidade dos dados apresentados, acredita-se na pertinência da hipótese de que o grau de evolução das representações dos sujeitos acerca de um objeto social qualquer é, tal como a teoria o prevê, lento, dependente de experiências significativas vividas pelos indivíduos e função ainda de certo "movimento", certa pré-disposição dos sujeitos em mudar sua visão em relação ao objeto em questão. O discurso social, a experiência vivida na prática docente, bem como as explicações, "teorias" elaboradas pelos sujeitos quando dessas situações, passam a ser mais significativas do que a formação acadêmica de alto nível como a pós-graduação (não concluída naquele momento). Pode-se supor que os conhecimentos, as habilidades adquiridas nessa fase da aprendizagem dos sujeitos ainda não teriam se integrado ao rol de experiências e co- 
nhecimentos adquiridos anteriormente na vida profissional prática dos indivíduos.

\section{Conclusões}

As relações entre linguagem audiovisual e aprendizagem parecem ainda guardar uma posição restrita e pouco elaborada nas concepções de profissionais ligados à educação, mesmo junto àqueles que se encontram em formação para a pesquisa. A qualidade das respostas mostrou pouca familiaridade dos indivíduos com o tema, pouco conhecimento do recurso e de seus benefícios potenciais dentro do processo ensino-aprendizagem. Foram respostas muito mais ligadas ao "senso comum" do que a uma reflexão aprofundada, fundamentada em modelos teóricos, como seria esperado de alunos de pós-graduação. Entende-se que tal fato possa ser assim visto, dado que a maioria dos sujeitos investigados não tinha nessa temática (linguagem audiovisual e aprendizagem) um interesse particular pela problemática em suas dissertações. Todavia, a importância de teorias de aprendizagem num programa de pósgraduação em Psicologia Escolar parece-nos fundamental, e poucos elementos das respostas fizeram referência a conceitos dessa natureza, de maneira mais aprofundada do que profissionais não capacitados nesse nível o fizeram.

Na mesma linha de raciocínio, notou-se que a fundamentação sobre a pertinência do uso foi calcada em fatos concretamente observáveis em sala de aula, não ligados de modo direto ao processo ensino-aprendizagem em si. Observações dos comportamentos apresentados pelos alunos, mas que não necessariamente refletem $o$ funcionamento psicológico referente ao tratamento da informação simbólica do sujeito, sustentavam parte da base de raciocínio feita pelos sujeitos. Nesse sentido, o recurso ao modelo de representações sociais na pesquisa permitiu não só evidenciar-se o conteúdo, algumas facetas dessas concepções dos sujeitos, mas também o levantamento de hipóteses da "origem" desses conceitos.
Nesse sentido, a prática efetiva com o recurso acabou funcionando como referencial de elaboração dessas "teorias" apresentadas pelos sujeitos. Nelas, a relação professor-suporte-aluno não apareceu de forma articulada: o suporte é bom ou ruim em si mesmo, para o aluno, quase numa relação reativa (E - R), sendo o aluno um "receptor transformado" pela ação do vídeo. No caso do professor, o vídeo em si não é bom nem mau; o que pode ocorrer é um uso inadequado do suporte pelo professor (que não sabe escolher qual vídeo usar, ou lhe falta formação sobre a maneira de utilizá-lo adequadamente), ou existem produtos de qualidade duvidosa.

Aparecem contradições nas argumentações. Como exemplos:

A relação professor-suporte-aluno é pouco aparente nas vantagens apresentadas. Podese supor que a ênfase da aprendizagem esteja no aluno; este precisa apenas ser "preparado" (através de um recurso "interessante" que o mobilize e desperte sua atenção) para a ação educativa do professor, que aparentemente "paira" sobre o processo ensino-aprendizagem. Quando essa relação é desmembrada, como aparece no caso das desvantagens atribuídas ao uso do vídeo, ela ocorre de forma incompleta. Ou a ênfase está no papel do professor, ou nas relações entre o vídeo e o aluno. As relações entre professor e suporte limitam-se a como o mesmo faz uso do recurso, ficando descoberta toda uma área de trabalho, de estabelecimento de relações entre objetivos pedagógicos a serem atingidos, e status, pertinência e função do uso da linguagem audiovisual na aprendizagem. Essa área deveria estar sendo profundamente buscada, na opinião das autoras, por parte dos sujeitos interessados em compreender processos de aprendizagem e uso de recursos tecnológicos.

Um outro exemplo é a dimensão lúdica do vídeo, apontada como vantagem, na medida em que chama a atenção do aluno para o tema a ser aprendido, sendo também um recurso "menos aborrecido" do que o material impresso convencional. Essa mesma dimensão é considerada como uma desvantagem, por confundir o apren- 
dizado com uma atividade de lazer, o que pode ser um indicador das concepções de aprendizagem que subjazem a esse tipo de argumentação.

Embora evidentemente haja limitações no estudo, visto que os dados coletados o foram exclusivamente via questionário simples e reduzido em perguntas, o conjunto desses elementos confirma, de maneira mais ampla, não só a pertinência do modelo de representações sociais para o estudo da problemática que envolve mídia $\mathrm{e}$ educação, mas também que o processo de evolução dessas representações é lento. O aspecto vivencial na construção de "teorias" dos sujeitos para explicar o mundo que os rodeia e sua situação nele é forte o suficiente para assegurar a construção de representações, que necessitarão de outras formas para evoluir do que a reflexão via formação em pesquisa.

\section{Referências Bibliográficas}

Bardin, L. (1996) L 'analyse de contenu. Paris: PUF.

Bélisle, C.; Butheau, R.; Jourdan, R.; Rosado, E.M.S. (1988) Communication médiatisée: étude de la pratique télévisuelle. Relatório de pesquisa IRPEACS/CNRS.

Fusari, M.F.R. (1986) Um espaço para o vídeo na formação de professores. In: M.M.K. Kunsch (org.) Comunicação e Educação: caminhos cruzados. São Paulo: Loyola.

Fusari, M.F.R. (1994). Televisão e vídeo na formação de professores de crianças. INTERCOM. 17 (1): 42-57, jan/jun. São Paulo.

Jodelet, D. (1984) Représentation sociale: phénomènes, concept et théorie. In: S. Moscovici (org.) Psychologie sociale. Paris: PUF.

Moliner, P. (1996). Images et représentations sociales. Grenoble: Presses Universitaires de Grenoble.

Moran, J.M. (1990) Os meios de comunicação na escola. Idéias, FDE, $\mathrm{n}^{\circ}$ 9: 21-28.
Moscovici, S. (1978) A representação social da Psicanálise. Traduzido do francês por A. Cabral, Rio de Janeiro: Zahar.

Osgood, C.E.; Suci, G.J. \& Tannenbaum, P.H. (1957) The measurement of meaning. Urbana: University of Illinois Press.

Pacheco, E.D. (1985) O pica-pau: herói ou vilão? Representação social da criança e reprodução da ideologia dominante. São Paulo: Loyola.

Pacheco, E.D. (org.)(1991) Comunicação, educação e arte na cultura infanto - juvenil. São Paulo, Loyola.

Penteado, H.D. (1991) Televisão e escola: conflito ou cooperação. São Paulo: Cortez.

Rosado, E.M.S. (1990) Communication médiatisée et processus d'évolution des représentations. Étude de cas: la représentation de l'informati$q u e$. Tese de Doutoramento. Université Lumière Lyon II. Lyon.

Rosado, E.M.S. (1992) Comunicação mediatizada e processo de evolução de representações. Estudo de caso: a representação da informática. Anais do I CONPE, ABRAPEE/ PUCCAMP, Campinas: Átomo: 160-163.

Rosado, E.M.S. (1994a) Comunicação mediatizada e formação. Estudo de caso: a representação da informática. Relatório técnico-científico / $\mathrm{CNPq}$ (in mimeo).

Rosado, E.M.S. (1994b) Vídeo e aquisição de conhecimentos: alguns elementos de uma metodologia de pesquisa. Intercom. 17 (2): 121-131, jan/jun. São Paulo

Silva, L.L.M. (1986). O espaço da comunicação no currículo de Pedagogia. In: M.M.K. Kunsch (org.) Comunicação e Educação: caminhos cruzados. São Paulo: Loyola.

Witter, C. (1992) A televisão e o adolescente: análise de conteúdo da programação preferida. Anais do I Congresso Nacional de Psicologia Escolar, ABRAPEE/PUCCAMP, Campinas: 231-234. 